DOE/ER/ $13676--4$

DE91 001778

\title{
A GENERAL PROCEDURE FOR
}

\section{THE SYNTHESIS OF PROCESS FLOWSHEETS}

\author{
Progress Report \\ for the period October 1, 1989 to September 30, 1990
}

J. M. Douglas and M. F. Malone

Department of Chemical Engineering

University of Massachusetts

Amherst, MA 01003

October 1990

prepared for

THE U. S. DEPARTMENT OF ENERGY

AGREEMENT NO. DE-FG02-87ER 13676

bing

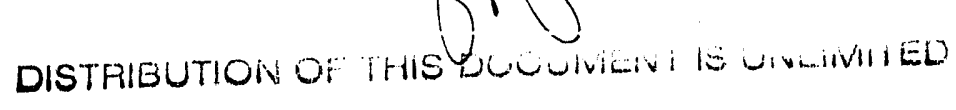




\begin{abstract}
This report is a summary of research progress in areas. The first is evaluating control systems for chemical plants at the conceptual design stage, including the effects of trace components, the desirable design modifications to improve dynamic control, developing short-cut dynamic models for complete plants, and control structures for distillation systems. Continuing work on a generalized approach to the synthesis of process flowsheets is also summarized. We discuss a general structure for the structure of processes involving vapor/liquid/liquid/solid separations along with a reiated short-cut method to describe liquid/liquid phase splits. The generalization of design methods to batch processing is also discussed.
\end{abstract}

\title{
NOT I CE
}

This report was prepared as an account of work sponsored by the United Siates Government. Neither the United States nor the Department of Energy, nor any of their employees, nor any of their contractors, subcontractors, or their employees, makes any warranty, express or implied, or assumes any legal liability or responsibility for the accuracy, compieteness, or usefulness of any information, apparatus, product or process dis closed or represents that its use would not infinge privately-owned rights. 


\section{INTRODUCTION}

The research in this reporting period was focused in two areas. The first of these was in "Screening Alternative Structures for Plant Control Systems," which was also the title of our contract for the period $2 / 1 / 87$ through $1 / 31 / 90$. The second area, which is the subject of our continuing work is "A General Procedure for the Synthesis of Process Flowsheets." Progress in each of these areas is summarized below in sections $I$ and $\Pi$, respectively.

\section{Plant Control Systems}

The goal of the study was to develop new procedures that could be implemented at the conceptual design of a plant in order to include the costs of control when comparing process alternatives that had about the same design costs. That is, an optimal design based on steady state considerations without accounting for disturbances is often not operable if the disturbances are considered and the design must be modified to make it possible to control the plant. The early work was focused on methods to determine operability in the face of disturbances and on the synthesis of control structures for complete plants, based on the steady state operability and minimum operating costs, and this work has been completed. In this period the results have been extended to include short-cut dynamic estimates and dynamic control, along with an addition to the procedure of a technique for including a 
sufficient number of exit points in the design to prevent the accumulation of trace components that enter with one of the feed streams or are produced by the reactions. We summarize each of these problems below.

\section{Trace Components}

Almost every company has designed some new process and then has found that the performance degrades within one or two weeks until eventually the process specifications cannot be met (either the product purity specification cannot be satisfied, a column no longer can achieve the desired separation, some equipment becomes saturated, etc.) because of the accumulation of inert, trace components within a recycle loop in the process. As a result, the process must be shut down and an additional exit point must be added to the flowsheet before the process is restarted. The cost of making design changes after a process has been built and started up are much greater than before start-up, because all the units must be cleaned out. However, we have developed a very simple procedure for identifying when a trace component may accumulate in a recycle loop has been developed so that additional exit points can be added before start-up is initiated. An early discussion of this work was given by Douglas (1989) and a more detailed paper is being prepared on this procedure for journal publication.

\section{Design Modifications Corresponding to Dynamic Control}

The problem of developing a dynamic model for a complete plant is so complex that detailed plant dynamic simulations are seldom attempted. However, when disturbances enter a process there is always a transient period of operation and when control systems are 
used to compensate for these disturbances, the manipulated variable must often overshoot the final desired steady state value. During this transient overshoot, the desired value of the manipulative variable often exceeds the maximum equipment capacity, so that the desired control action cannot actually be achieved. However, by adding additional equipment capacity to the design it is possible to insure that no constraint will be encountered. We have developed a procedure for assessing the loss of performance because of encountering a constraint vs. the incremental cost of adding extra design capacity. A paper is currently being prepared on this topic.

\section{Short-Cut Dynamic Models for Complete Plants}

In order to estimate the overshoot resulting from the entrance of a disturbance into a plant or the effect of control to compensate for the disturbance, it is necessary to have a dynamic model of the plant available. The goal of our dynamic simulation and control evaluation is to see if modifications to the design are required, so short-cut models will provide sufficient accuracy. A model of this type has been developed that allows quick evaluation of alternative control systems, and a paper is being prepared describing the results.

\section{Control Structures for Distillation Systems}

The steady-state characteristics of complex distillation configurations have been studied to develop a procedure for screening candidate designs that have poor steady-state control characteristics. A reduced order technique, orthogonal collocation, was used to construct performance models. The results have been used to screen control schemes for nonideal binary mixtures and to compare various control schemes for sidestream columns for ternary mixtures. For the ternary mixtures, at least 16 alternative control schemes were 
ruled out in each of several cases and at least one of the remaining alternatives used the reflux ratio to control the top purity. The case of a double-feed/sidestream column was also studied and schemes that control the sidestream purity with the bottoms liquid flow are always ruled out. In fact, based on very poor steady state control characteristics of the double-feed/sidestream configurations, a modified design is preferred. DeGuiran and Malone (1989a, 1989b) described some of this work and a more detailed description for journal puhlication is in preparation.

\section{Synthesis of Process Flowsheets}

Our recent work has been focused on developing a more general procedure for the synthesis of process flowsheets. In our original early work, the hierarchical synthesis procedure was limited to continuous vapor/liquid systems. We are currently working on generalizing the approach to include solids and liquid-liquid processing operations and to batch processes.

Processes involving solids handling and separations and/or liquid/liquid separations are different than vapor/liquid processes because the operation of decanters, dissolvers, and crystallizers each have optimum operating temperatures. Hence, the common energy integration techniques, which have led to major energy savings, must be modified to handle this class of problems. In addition, finding the "best" process alternative should lead to both raw material and energy savings with lower capital costs as shown in some of our earlier 
work on vapor-liquid systems (Terrill and Douglas, 1987). For this reason a systematic procedure for generating process alternatives and procedures for the quick screening of these alternatives should be particularly useful.

\section{Short-Cut Calculations of Liquid/Liquid Phase Splits}

Rigorous calculations of liquid/liquid phase splits require iteration and are very tedious. Since the liquid/liquid equilibrium calculations affect the reactor and separation system recycle flows (which also require iteration for rigorous calculations), the process material balances normally require a major computational effort. However, the costs of various process alternatives often vary by an order of magnitude so that for screening calculations approximate short-cut calculations are adequate. We have developed a short-cut procedure for liquid/liquid phase splits that can be used with our short-cut material balances for reactor recycles so that we can use function evaluations to estimate the process flows.

\section{Phase Splits for Vapor/Liquid/Liquid/Solid Separations}

A new structure for to accomplish phase splits for vapor/liquid/liquid/solid systems has been identified. In addition, a new process alternative formulation for the synthesis of the vapor recovery, organic liquid separation, aqueous liquid separation, and solid recovery systems is being developed.

\section{Evaluation of the Procedures}

We have identified approximately $2 ; 0$ processes that have interesting vapor/liquid/liquid/solid flowsheet structures. We are using these as case studies to evaluate the results by combining the results from items 5 and 6 above with the existing hierarchical 
procedure for conceptual design.

\section{Batch Processing}

The problem of production scheduling is much more tightly coupled to the design problem in many batch or other noncontinuous processes. In addition, in the batch design problem it is often desired to select from an available set of equipment units instead of, or possibly in addition to, purchasing new equipment. We are studying batch processing using simulated annealing and have demonstrated the approach on the scheduling problem using an economic objective with due date and inventory penalties (Malone, 1989). Future work will focus on incorporating the choice of equipment using short-cut models and possibly some heuristics for batch processes similar to those developed in our earlier work on continuous processes.

\section{ADMINISTRATIVE}

The principal investigators have complied with the basic terms of the Agreement. Each of the investigators has devoted $15 \%$ of time during the academic year and $33.3 \%$ of time during the summer to this project and the same percentage of time is expected to be devoted during the remainder of the project. 


\section{LITERATURE CITED}

J. M. Douglas, "Modifying Process Flowsheets to Improve Process Control," Proceedings of the Seventh Symposium on Energy Engineering Sciences. Nonlinear Mechanics and Mechanical Systems, Argonne National Laboratory, Argonne; ILL, June 19-21, 1989. pp. 114-20.

M. DeGuiran and M. F. Malone, "Screening Steady-State Control Structures for Distillation System Design," Proceedings of the Seventh Symposium on Energy Engineering Sciences. Nonlinear Mechanics and Mechanical Systems, Argonne National Laboratory, Argonne, ILL, June 19-21, 1989a. pp. 121-28.

M. DeGuiran and M. F. Malone, "Steady-State Control Considerations for Distillation System Designs," paper 167Bm, AIChE Annual Meeting, San Francisco, CA, November, $1989 b$.

D. L. Terrill and J. M. Douglas, Industrial and Engineering Chemistry Research, 26, 685 (1987).

M. F. Malone, "Batch Sequencing by Simulated Annealing," paper 23f, AlChE Annual Meeting, San Francisco, CA, November, 1989. 

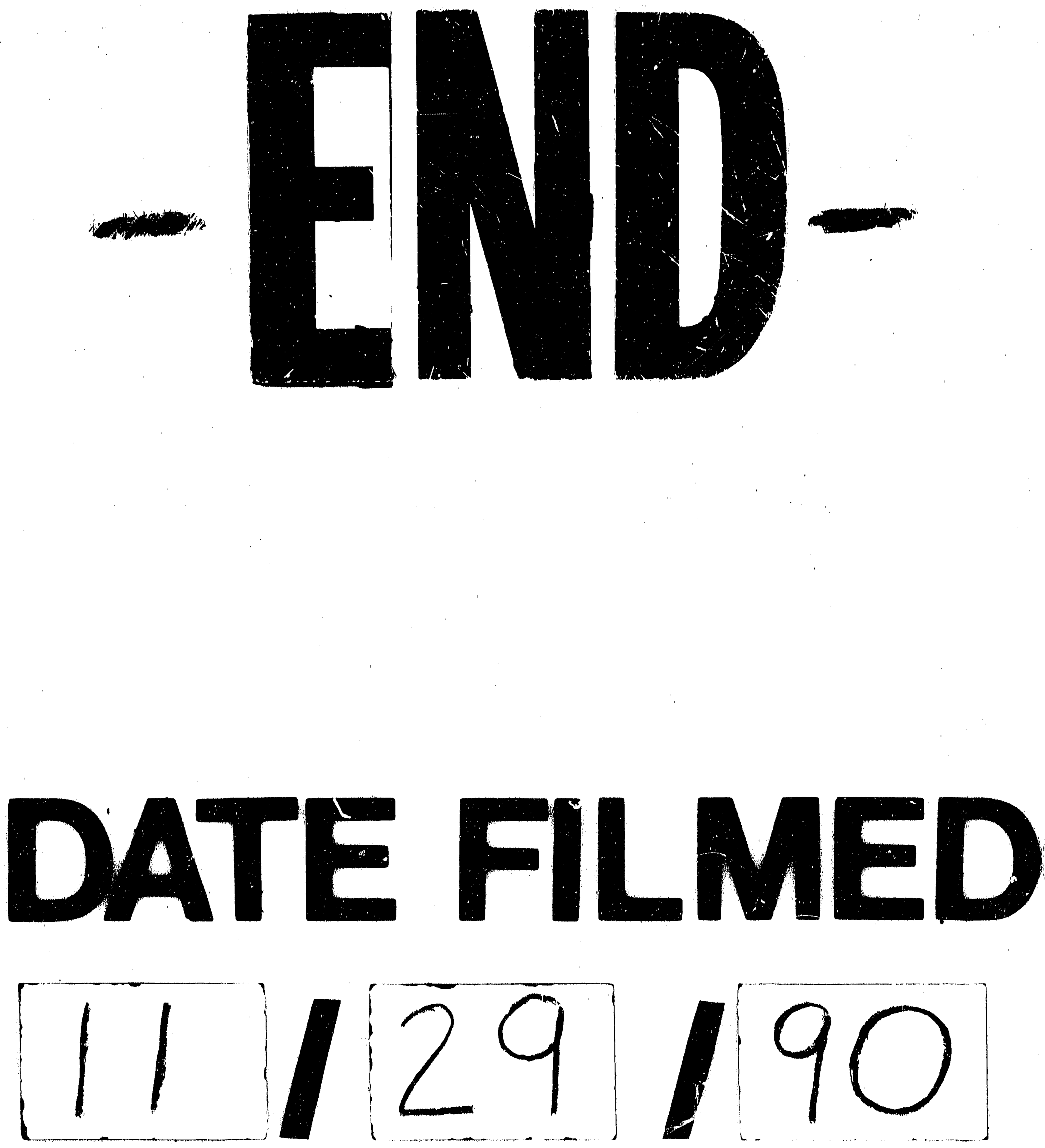
